\title{
Malignant pleural and peritoneal mesotheliomas in former miners and millers of crocidolite at Wittenoom, Western Australia
}

\author{
G Berry, N H de Klerk, A Reid, G L Ambrosini, L Fritschi, N J Olsen, E Merler, A W Musk
}

See end of article for authors' affiliations

Occup Environ Med 2004;61:e14 (http://www.occenvmed.com/cgi/content/full/61/4/el4).

.....................

Correspondence to: Emeritus Professor $G$ Berry, School of Public Health, Edward Ford Building A27, University of Sydney, New South Wales 2006, Australia; geoffb@ health.usyd.edu.au

Accepted

5 September 2003

\begin{abstract}
Aims: To report the number of malignant pleural and peritoneal mesotheliomas that have occurred in former Wittenoom crocidolite workers to the end of 2000, and to compare this with earlier predictions. Methods: A group of 6493 men and 415 women who had worked at the former Wittenoom crocidolite mine and mill at some time between 1943 and 1966 have been followed up throughout Australia and Italy to the end of 2000.

Results: The cumulative number of mesotheliomas up to 2000 was 235 in men (202 pleural, 33 peritoneal) and seven (all pleural) in women. There had been 231 deaths with mesothelioma (9\% of known deaths). Conclusions: The number of deaths in men with mesothelioma between 1987 and 2000 was at the low end of the predictions made earlier based on the number of cases to 1986. If this trend continues, it is predicted that about another 110 deaths with mesothelioma will occur in men by 2020 .
\end{abstract}

$\mathrm{T}$ he mortality to 1977 and other health effects of miners and millers employed at the Wittenoom crocidolite asbestos mine in Western Australia was first published in $1980 .^{1}$ The mortality up to 1980 was given by Armstrong and colleagues, ${ }^{2}$ and a further update for lung cancer, mesothelioma, and pneumoconiosis to 1986 by de Klerk and colleagues. ${ }^{3}$ Preliminary results for mesothelioma to 1999 were given by Musk and colleagues. ${ }^{4}$ In this paper we present mesothelioma incidence and mortality up to the end of 2000, compare the observed numbers from 1987 to 2000 with predictions that were made from the number occurring up to $1986,{ }^{35}$ and analyse the survival time after diagnosis. A more detailed presentation of mortality by a range of causes in relation to expected mortality will be published separately.

\section{METHODS}

Crocidolite (blue asbestos) was mined at Wittenoom Gorge in Western Australia from 1937 until 1966. From 1943 a single company (the Australian Blue Asbestos Company) was involved and details of employees of this company were obtained from employment records supplemented by information from a mineworkers' benevolent fund. ${ }^{2}$ Some of the characteristics of the workforce have been reported previously: ${ }^{2}$ duration of employment was usually short, with $45 \%$ of men working at Wittenoom for less than three months and less than 3\% remaining for five years or longer. Dust concentrations, particularly in the old mill, were high: only one study of airborne fibre levels was carried out and the estimated time weighted fibre concentrations derived from the results have been described as underestimates of exposure by the person who performed the original study. ${ }^{\circ}$ Almost $90 \%$ of the men worked in the mine, mill, or both, but few of the women had worked in the mine or mill and consequently their exposures were lower.

This analysis is of 6493 men and 415 women; these numbers differ slightly from those reported previously $(6502$ men and 410 women $^{3}$ ) since we have more accurately identified people with similar names previously thought to be the same person and removed some duplicates. Mortality was assessed using the Australian National Death Index, and cancer incidence using the Australian Cancer Statistics Clearing House, Western Australian Mesothelioma Registry, and Australian Mesothelioma Registry. There is some additional information available for 2001 and 2002 from Western Australia but the follow up is incomplete for these years. The largest number of migrants from non-English speaking countries working at Wittenoom was from Italy. Untraced subjects with an Italian name have been searched in Italy, and their vital status assessed. The clinical records of those who died from primary pleural and peritoneal tumours allowed the identification of mesotheliomas. ${ }^{7}$ The follow up is based on matching of deaths and cancer notifications but not all those for whom a match was not found are necessarily still alive and free of cancer. The accuracy of matching of mesotheliomas occurring with Western Australia is probably high since all cases in Western Australia are subjected to detailed investigation by a Mesothelioma Registry Committee, and many are referred to the Sir Charles Gairdner Hospital where a full occupational history is taken. Furthermore, the analyses presented in this paper do not depend critically on the trace rate. By the end of 2000, 2449 of the men and 100 of the women were known to have died. In this paper attention is restricted to those dying with mesothelioma, including all deaths of men or women known to have died with a mesothelioma irrespective of the coded cause of death.

\section{RESULTS}

The first mesothelioma was notified in November 1960 and the second in October 1969. Thereafter mesotheliomas were notified regularly and up to the end of 2000 there had been 235 cases in men ( 202 pleural and 33 peritoneal), and seven in women (all pleural). The first death with a mesothelioma was recorded in 1961, the second in 1969, and up to the end of 2000 there had been 224 deaths in men with mesotheliomas ( 192 pleural and 32 peritoneal), and seven in women (all pleural) as shown in table 1 . In addition another eight are known to have died in 2001 or 2002, and analyses of survival and lag time are based on 239 deaths. 


\section{Main messages}

- There is a high continuing toll from the Wittenoom mine and mill which closed over 35 years ago, but fortunately not as high as some of the earlier predictions.

Table 2 tabulates the lag time from date first started at Wittenoom to date of death with mesothelioma. The shortest lag time was 13 years and 5 months and the longest so far recorded is 53 years. The average lag time was 32.9 years but because the industry closed 36 years ago, this average and the age of survivors will inevitably rise as follow up continues, as also will the numbers in the categories of 35 years or more in table 2. The shortest lag time to diagnosis was 12 years and 5 months.

Based on an analysis of 84 deaths with mesothelioma in men to the end of 1986, predictions were made of the number occurring up to $2020 .^{5}$ The general model of the mesothelioma death rate in relation to time since first exposure used was

$$
\text { rate }=\mathrm{c}(\mathrm{t}-\mathrm{w})^{\mathrm{k}} \exp (-\lambda \mathrm{t})
$$

where $\mathrm{c}$ is related to cumulative exposure, $\mathrm{t}$ is time since first exposure, $\mathrm{k}$ is a power, $\mathrm{w}$ is a lag time following exposure during which it was assumed that mesotheliomas would not occur, and $\lambda$ is a rate of elimination of crocidolite from the lungs. Five cases of this model were used and in this paper attention is restricted to three, the simplest power relationship with no lag period or elimination, and the two allowing for elimination:
- Model $\mathrm{l}: \mathrm{k}=3.5$, and both the lag and the rate of elimination zero, that is rate $=\mathrm{ct}^{\mathrm{k}}$

- Model 2: $\mathrm{k}=3.9$, lag $\mathrm{w}=5$ years; rate of elimination $\lambda=6.8 \%$ per year

- Model 3: $\mathrm{k}=5.4$, lag $\mathrm{w}=5$ years; rate of elimination $\lambda=15 \%$ per year.

De Klerk and colleagues ${ }^{3}$ based their predictions on model 1 and obtained similar predictions to Berry. ${ }^{5}$ Table 3 presents the predicted numbers under the three models and the observed number up to the end of 2000. The observed numbers are slightly lower than the predictions under model 3. In fig 1 the predicted and observed cumulative number of mesothelioma deaths are plotted against calendar year.

For the 242 men and women with mesothelioma, 239 are known to have died. Of these, nine were not diagnosed until death. For the other 230 who have died with mesothelioma, the median survival from diagnosis was 8.3 months (interquartile range 4.5 to 16.9 months). Seven survived for three years or more $(3.1,3.2,3.6,3.7,4.5,4.6$, and 6.7 years $)$. There are no known long term survivors among the three not known to be dead (two were diagnosed in 2000, and the third was lost track of overseas after diagnosis in 1985). Survival has not increased much over time; for those diagnosed before $1981(\mathrm{n}=42)$ the median survival was 7.6 months, for those diagnosed during $1981-90(\mathrm{n}=88)$ it was 8.0 months, and for those diagnosed in 1991-2000 $(n=100)$ the median survival was 8.6 months.

Age at diagnosis increased over time and in view of a possible association of survival with age, ${ }^{8}$ survival time was analysed allowing for age at diagnosis. For those aged less than 60 years at diagnosis $(n=124)$ the median survival was 8.8 months, and for those diagnosed at age 60 years or older $(\mathrm{n}=106) 7.7$ months. The transform log (months survival + 1) was approximately normally distributed and a two way

Table 1 Deaths with mesothelioma by period

\begin{tabular}{lccccc}
\hline & \multicolumn{2}{l}{ Men } & & & \\
\cline { 2 - 4 } Period & Pleural & Peritoneal & Total & Women (all pleural) & Total \\
\hline $1961-65$ & 1 & 0 & 1 & 0 & 1 \\
$1966-70$ & 3 & 0 & 3 & 0 & 3 \\
$1971-75$ & 10 & 0 & 10 & 0 & 10 \\
$1976-80$ & 18 & 4 & 22 & 1 & 23 \\
$1981-85$ & 32 & 5 & 37 & 1 & 38 \\
$1986-90$ & 48 & 5 & 53 & 1 & 54 \\
$1991-95$ & 41 & 6 & 47 & 3 & 52 \\
$1996-00$ & 39 & 12 & 51 & 1 & 231 \\
Total & 192 & 32 & 224 & 7 & \\
\hline
\end{tabular}

Table 2 Lag time between starting at Wittenoom and death with mesothelioma

\begin{tabular}{lccccc}
\hline & \multicolumn{2}{l}{ Men } & & & \\
\cline { 2 - 4 } Lag (years) & Pleural & Peritoneal & Total & Women (all pleural) & Total \\
\hline $11-15$ & 1 & 0 & 1 & 0 & 1 \\
$15-19$ & 12 & 0 & 12 & 0 & 12 \\
$20-24$ & 24 & 4 & 28 & 0 & 28 \\
$25-29$ & 32 & 3 & 35 & 3 & 38 \\
$30-34$ & 52 & 6 & 58 & 3 & 61 \\
$35-39$ & 45 & 12 & 57 & 1 & 58 \\
$40-44$ & 30 & 6 & 46 & 0 & 4 \\
$45-49$ & 3 & 1 & 1 & 0 & 1 \\
$50-54$ & 1 & 0 & 232 & 7 & 239 \\
Total & 200 & 32 & & 0 & 4 \\
\hline
\end{tabular}




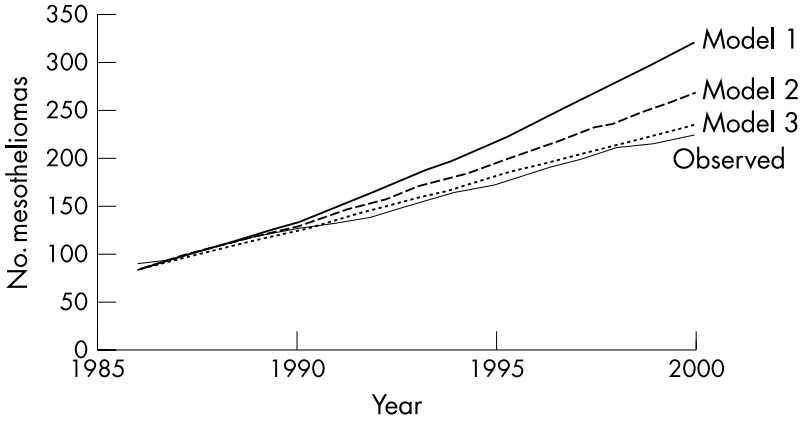

Figure 1 Predicted cumulative number of mesothelioma deaths in men from 1987 to 2000 under three models, and observed number.

analysis of variance of the transformed values showed that the greater survival for those diagnosed at younger ages was statistically significant $(p=0.003)$, while the difference between the three periods was not $(p=0.67)$. After allowing for age at diagnosis the increase in survival time over the three periods was 1.3 months.

\section{DISCUSSION}

By the end of 2000 the number of mesothelioma deaths had reached $3.4 \%$ of all the male workers and $1.7 \%$ for the females. Nine per cent of known deaths in men and $7 \%$ in women were with mesothelioma. The true rates may be a little higher since it is known that some former workers emigrated from Australia and were lost to follow up, although some mesotheliomas occurring in Italy have been identified and included. The higher rate in men is not surprising as they are known to have been exposed to higher levels of crocidolite in the mines and mills. The number occurring in the period 1987 to 2000 was similar to the lowest predictions made based on the number up to 1986, and this provides some evidence that models of mesothelioma incidence that incorporate an allowance for a gradual elimination of crocidolite from the lungs after exposure are more realistic. There is good evidence from other sources that such elimination does occur and that for crocidolite the rate of elimination is in the range of 0.1 to 0.15 a year corresponding to a half-life of between 5 and 7 years. ${ }^{9}$ The relevance of clearance from the lungs with respect for peritoneal mesotheliomas is unknown, but as $86 \%$ of the mesotheliomas were pleural, would not have influenced our results greatly.

The predictions were based on the assumption that there were no other factors operating that might influence incidence of mesothelioma or survival following diagnosis. From the evidence presented in this paper survival following diagnosis has not improved over the past 25 years. About a third of the group of former workers have been involved in a prophylactic trial since 1990 with beta carotene and retinol aimed at reducing the incidence of mesothelioma and other cancers. The results from the first five years indicated that people taking retinol had a risk ratio for developing mesothelioma of 0.36 (95\% CI 0.10 to 1.0 ) compared with those taking beta carotene ${ }^{10}$ Further, the risk of mesothelioma in subjects in the prevention programme was $23 \%$ lower than in those not taking part, after adjustment for asbestos exposure. ${ }^{11}$ This could therefore have had the effect of reducing the number of cases by about $1 / 12$ th-that is, by about 10 cases, between 1990 and 2000 .
Table 3 Predicted and observed number of mesothelioma deaths in men 1987-2000

\begin{tabular}{lcccc}
\hline \multirow{4}{*}{ By end of year } & \multicolumn{2}{l}{ Predicted (cumulative) } & \\
\cline { 2 - 4 } & Model 1 & Model 2 & Model 3 & Observed \\
\hline 1986 & $84^{*}$ & $84^{*}$ & $84^{*}$ & $89 \dagger$ \\
1990 & 133 & 128 & 124 & 126 \\
1995 & 216 & 194 & 180 & 173 \\
2000 & 320 & 267 & 234 & 224 \\
\hline \multirow{2}{*}{ *Observed number as known at the time of prediction. } \\
TObserved number revised in current update.
\end{tabular}

If the occurrence of mesotheliomas continues at the lowest end of the set of predictions made after 1986, then there would be about a further 110 deaths in men due to mesothelioma by the end of 2020. This is a high continuing toll from the Wittenoom mine and mill which closed over 35 years ago, but fortunately not as high as some of the earlier predictions.

\section{ACKNOWLEDGEMENTS}

We are grateful to CSR Australia for providing the employment records of Australian Blue Asbestos, the Western Australian Cancer Registry (Dr Timothy Threlfall), and the Australian Mesothelioma Registry (Dr Jim Leigh). Mr Philip Etherington and Ms Jan Sleith were responsible for the database. This study was funded by the National Health and Medical Research Council of Australia and was approved by the University of Western Australia's Human Research and Ethics Committee.

\section{Authors' affiliations}

G Berry, School of Public Health, University of Sydney, New South Wales 2006, Australia

N H de Klerk, A Reid, G L Ambrosini, L Fritschi, A W Musk, School of Population Health, University of Western Australia

N J Olsen, Sir Charles Gairdner Hospital, Nedlands, Western Australia 6009

E Merler, Occupational Health Unit, Department of Prevention, Local Health Unit, National Health System, Padua, Italy

\section{REFERENCES}

1 Hobbs MST, Woodward SD, Murphy B, et al. The incidence of pneumoconiosis, mesothelioma and other respiratory cancer in men engaged in mining and milling crocidolite in Western Australia. In: Wagner JC, ed. Biological effects of mineral fibres. IARC Scientific Publication No. 30. Lyon: International Agency for Research on Cancer, 1980:615-625.

2 Armstrong BK, de Klerk NH, Musk AW, et al. Mortality in miners and millers of crocidolite in Western Australia. Br J Ind Med 1988;45:5-13.

3 de Klerk NH, Armstrong BK, Musk W, et al. Predictions of future cases of asbestos-related disease among former miners and millers of crocidolite in Western Australia. Med J Aust 1989;151:616-20.

4 Musk AW, de Klerk NH, Olsen NJ, et al. Mortality in miners and millers of crocidolite in Western Australia: follow-up to 1999. Ann Occup Hyg 2002;46(suppl 1):90-2.

5 Berry G. Prediction of mesothelioma, lung cancer, and asbestosis in former Wittenoom asbestos workers. Br J Ind Med 1991;48:793-802.

6 Rogers A, Major G. The quantitative risks of mesothelioma and lung cancer in relation to asbestos exposure: the Wittenoom data. Ann Occup Hyg 2002:46:127-8.

7 Merler E, Ercolanelli $M$, de Klerk N. Identificazione e mortalità dei migranti italiani, ritornati in Italia, che hanno lavorato alla miniera di crocidolite di Wittenoom Gorge, Western Australia. Epidemiol Prev 2000;6:255-61.

8 Magnani C, Viscomi S, Dalmasso P, et al. Survival after pleural malignant mesothelioma: a population-based study in Italy. Tumori 2002;88:266-9

9 Berry G. Models for mesothelioma incidence following exposure to fibers in terms of timing and duration of exposure and the biopersistence of the fibers. Inhal Toxicol 1999:11:111-30.

10 de Klerk NH, Musk AW, Ambrosini GL, et al. Vitamin A and cancer prevention II: comparison of the effects of retinol and beta-carotene. Int J Cancer 1998;75:362-7.

11 Musk AW, de Klerk NH, Ambrosini GL, et al. Vitamin A and cancer prevention. I:, Observations in workers previously exposed to asbestos at Wittenoom, Western Australia. Int J Cancer 1998;75:355-61. 